\title{
A INFLUÊNCIA DO CRM SOCIAL NO DESEMPENHO DE NEGÓCIOS DE MICROEMPREENDEDORES: UM ESTUDO DE CASO NO SETOR DE VESTUÁRIO.
}

\author{
Eric David Cohen, Mariah Schevenin da Silva*.
}

\begin{abstract}
Resumo
Este projeto de iniciação cientifica traz um estudo de caso de microempresas do setor de vestuário, no qual foi realizada a avaliação da influência do marketing de mídias sociais na utilização do CRM da empresa, e a consequente comparação da satisfação do desempenho do negócio a partir do ponto de vista dos microempreendedores. Neste contexto, o objeto principal de estudo é o uso do CRM Social como ferramenta de desenvolvimento do negócio. A pesquisa coletou dados de duas microempresas do setor, que demonstraram que o uso intenso das mídias sociais para o CRM da empresa tende a proporcionar maior satisfação com o desempenho de negócios na perspectiva dos microempreendedores.
\end{abstract}

\section{Palavras-chave:}

CRM Social, Microempreendedor, Mídias Sociais.

\section{Introdução}

Essa pesquisa tem como objetivo analisar a influência das mídias sociais como ferramenta de gestão no relacionamento com clientes, para promover 0 desempenho de microempresas do setor de vestuário, bem como para analisar a satisfação do desempenho do negócio do ponto de vista dos empreendedores.

No Brasil, o setor de vestuário reúne mais de 79,3 mil empresas, das quais mais de $98 \%$ são confecções de micro e pequeno porte (Instituto de Desenvolvimento Industrial do Espírito Santo - IDEIES, 2017).

Segundo a Sociedade Brasileira de Varejo e Consumo (SBVC), o comércio eletrônico vem se consolidando como uma das principais forças motrizes do varejo brasileiro e este crescimento acelerado é a ponta do iceberg de um intenso processo de transformação digital pelo qual as empresas estão passando.

\section{Resultados e Discussão}

As escalas de mensuração utilizadas neste estudo para mensurar os conceitos nas hipóteses foram desenvolvidas por Charoensukmongkol e Sasatanun (2017), que criaram escalas a partir de uma série de etapas sugeridas por pesquisadores anteriores (DEVELLIS, 1991; NETEMEYER, BEARDEN \& SHARMA, 2003). Elaborou-se um questionário auto administrado para coleta de dados. Estes questionários foram distribuídos pessoalmente pela pesquisadora.

A partir das informações obtidas, constatou-se que as duas microempresas utilizam as interações entre clienteempresa nas mídias sociais para personalizar seus produtos e serviços, de forma a integrar o cliente ao planejamento e estratégias da empresa, fazendo-o sentirse como se fosse parte da empresa que escolheu interagir, gerando satisfação e retenção dos mesmos.

\section{Conclusões}

Ao vender roupas pela internet, os lojistas deparam-se com diversos fatores que afetam diretamente a escolha do consumidor: caimento da peça, se o tamanho escolhido se adequa às medidas do corpo e se o tecido é de boa qualidade. Quando o assunto é roupa, um dos maiores problemas da compra online é a ausência da experiência sensorial. Não poder tocar e sentir o produto, muitas vezes leva o consumidor a desistir de adquiri-lo (COUTO; RODRIGUES; PEDRO, 2014).

Ambas as empresas utilizam as interações pelas redes sociais (Instagram) para personalizar e demonstrar cada detalhe da composição de seus produtos, este é um exemplo essencial do valor para o cliente em um modelo de CRM Social - a imersão em uma experiência que atende às necessidades de "fornecimento de valor" do cliente (GREENBERG, 2009).

BELEW, Shannon. The Art of Social Selling; finding and engaging customers on Twitter, Facebook, LinkedIn, and other social networks. Special ed. [S.L] AMACOM, 2014

COUTO, L., RODRIGUES, J. R., PEDRO, E. S. A roupa sob medida no ecommerce de moda. $2^{\circ}$ Congresso Científico Têxtil e de Moda. Disponível em: www.contexmod.net.br/index.php/segundo/article/view/139. Acesso em

15 maio2018.

E-BIT.Relatório Webshoppers 2017. Disponível

<https://www.ebit.com.br/webshoppers>. Acesso em: 12jan2019.

E-BIT.Relatório Webshoppers 2018. Disponível

<https://www.ebit.com.br/webshoppers>. Acesso em: 12 jan2019.

E-BIT.Relatório Webshoppers 2019. Disponível

<https://www.ebit.com.br/webshoppers>. Acesso em: 12jan2019.

GREENBERG, Paul. CRM at the Speed of Light, Fourth Edition: CRM Social 2.0 Strategies, Tools, and Techniques for Engaging Your Customers. 4 ed. New York: McGraw-Hill Education, 2009.

HASHAI, N., Sequencing the expansion of geographic scope and foreign operations by "born global" firms, Journal of International Business Studies, 42 (8), pp. 995-1015, 2011.

INSTITUTO DE DESENVOLVIMENTO INDUSTRIAL DO ESPIRITO SANTO - IDEIES. Análise de Competitividade do Setor das Indústrias do Vestuário do Estado do Espírito Santo. Disponível em: <https://sedes.es.gov.br/Media/sedes/Contratos\%20de\%20competitividade/An\% C3\%A1lises\%20de\%20Competitividade/Vestuario\%20Analise\%20Compet $\% 202$ 017.pdf>. Acesso em: 11 jan2019.

KOTLER, P., ARMSTRONG, G. Princípios de Marketing; Tradução Sabrina Cairo. 15 ed. São Paulo: Pearson Education do Brasil, 2015.

KOTLER, P., KARTAJAYA H., SETIAWAN, I.. Marketing 4.0: do tradicional ao digital. Tradução: Ivo Korytowski. Rio de Janeiro: Sextante, 2017.

ROCHA, Marcelo. Microempresas no Brasil: análise do período de 1984 a 2005. Revista Eletrônica de Administração. Disponível em:<http://www.redalyc.org/articulo.oa?id=401137460008>. Acesso em: 20 abril 2018.

SOCIEDADE BRASILEIRA DE VAREJO E CONSUMO. Ranking SBVC: 50 maiores empresas E-commerce Brasileiro: um estudo completo do Ecommerce. Disponível em: <http://sbvc.com.br/wpcontent/uploads/2018/12/ranking_ecommerce-2018.pdf>. Acesso em: 14jan2019. SONNEVELD, S. et al. Varejo No Brasil: A Influência Do Digital Sobre 0 Consumo. The Boston Consulting Group. Disponível em: <http://image.bcgemail.com/lib/feca167375620574/d/1/BCG_Varejo\%20no\%20Brasil_Influencia \%20do\%20Digital\%20no\%20Consumo_Dez\%202015.pdf > . Acesso em 11 jan 2019 . 